\title{
LA CONTABILIDAD Y LA AUDITORIA REQUIEREN DE SÓLIDOS REFORZAMIENTOS EN EL PRESENTE SIGLO XXI
}

Dr. Ernesto Polar Falcón*

El 20 de abril de 2001, los auditores nacionales, contratados por el Colegio de Contadores Públicos de Lima, representantes de una firma transnacional de la misma actividad, emitieron el DICTAMEN DE LOS AUDITORES INDEPENDIENTES, dirigido al Consejo Directivo, con su opinión sobre el balance general, estado de ingresos, gastos y cambio en el patrimonio institucional y el estado de flujo de efectivo al 31 de diciembre de 2000.

La última parte del primer párrafo del ındicado DICTAMEN dice:

"No hemos efectuado revisión alguna de los estados de ingresos, gastos y cambios en el patrimonio institucional y de flujos de efectivo por el año terminado el 31 de diciembre de 1999 que se presenta únicamente para propósitos comparativos.

Sin embargo, hemos auditado el balance general al 31 de diciembre de 1999 y los estados de ingresos, gastos y cambios en el patrimonio institucional y de flujo de efectivo por el período de tres meses terminado en esa fecha, sobre los que en nuestro dictamen de fecha 14 de abril de 2000 expresamos una opinión que contiene una salvedad POR ELEFECTO DE RECONOCER LOS INGRESOS POR CUOTAS DE SUS ASOCIADOS SOBRE LA BASE

\author{
DEL DEVENGADO EN VEZ DE \\ SOBRE LA BASE DEL PERCIBIDO \\ COMO LO ESTABLECEN LOS \\ PRINCIPIOS DE CONTABILIDAD \\ GENERALMENTE ACEPTADOS".
}

Se anota con letras mayúsculas los últimos renglones, para resaltar que desde 1942, fecha de fundación del Colegio de Contadores Públicos de Lima, hasta el año 1999, o sea por 57 años, los ingresos por cuotas de sus asociados se han registrado en los libros oficiales sobre la base de devengado, procedimiento contrario a los principios de contabilidad; signo inequívoco del mínimo interés que se da a éstos y de los resultados contables periódicos que con poca frecuencia distribuye la institución

Asimismo, que en muchas oportunidades se han efectuado auditorías financieras en el Colegio Profesional sin que se haya expresado salvedad alguna por los registros contables de los ingresos sobre la base de devengado.

Recién, a partir del año 2000 los ingresos por cuotas de asociados se reconocen sobre la base de lo percibido: El efecto de la corrección de esta situación, según lo dice la Nota 2-j) a los Estados Financieros Auditados al 31 de diciembre de 2000, "ascendió a S/. 2,125,057 y se afectó a los rubros de cuentas por cobrar a asociados y el patrimonio institucional". 
El balance general al 31 de diciembre de 2000 , muestra un monto de S/. 105,713 en cuentas por cobrar a asociados frente al monto de S/. 2,310,238 que se tenía en 1999; y un patrimonio institucional que tiene un monto de S/. 2,741,395 frente a S/. 4,876,823 que se mostraba en 1999.

También en el mismo párrafo del DICTAMEN que se está analizando, los auditores expresan loque a continuación se resume:

\section{No revisado}

Estado de ingresos, gastos y cambios en el patrimonio institucional - 1999

Estado de flujos de efectivo - 1999

\section{Se ha auditado}

Balance general 1999

Y de los 3 últimos meses de 1999

Estado de ingresos, gastos y cambios en el patrimonio institucional

Estado de flujos de efectivo

Se concluyen estos análisis con los siguientes comentarios:

1. Por un lado, el Colegio de Contadores Públicos de Lima, entidad representativa de la profesión contable en Lima Metropolitana y modelo de ejemplo a los demás Colegios Profesionales de provincias, registraba los ingresos de sus asociados aplicando un procedimiento contrario a los principios de contabilidad.

2. Por otro lado, presumiblemente, de común acuerdo con el Colegio Profesional, los auditores anotan lo que no revisaron y lo que sí auditaron, sin que se encuentre sustentación alguna de las razones que lo motivaron.
3. Es decir, se observa en el Perú y en Lim. Metropolitana en particular, un caso específico de incumplimiento de la normatividad contable vigente y de la toma de decisiones sobre lo que se debe auditar y lo que no se debe auditar. Estos procedimientos se aplicaron sin mayores explicaciones contables y han sido prácticamente aprobados al no levantarse protesta alguna por los miembros de la orden. Fueron decisiones entre una institución profesional y una sociedad de auditoría, obteniéndose como conclusión, que se han tomado decisiones que en una $u$ otra forma, afectan los procesos establecidos en las ciencias contables, que son consideradas como el pendón inmaculado de la noble y sagrada profesión del Contador Público.

Este pequeño caso que se acaba de explicar, nos conduce a la siguiente pregunta: ¿Cuántos casos similares de mayor o menor envergadura han sucedido, están sucediendo o sucederán en el Perú, sin que mayormente preocupe en lo más mínimo a ninguna institución fiscalizadora ni a los componentes de la profesión?

Y si se observa al mundo altamente industrializado, con países de indudable liderazgo contable, que en forma continua nos envían nuevas normas y procedimientos de contabilidad y auditoría para aplicarlos en las complicadas operaciones que trae la globalización. En el mes de enero de 2002, sucede un caso estremecedor en los Estados Unidos, la empresa Enron Corp., gigante energético con sede en Houston, quiebra en medio de un caos contable y financiero, que ha removido las tradicionales estructuras de control contable y financiero de los EE. UU.

Leamos con detenimiento, lo que explica el redactor de The Wall Stret Joumal, Sr. Jonathan Weil, al inicio del problema de la quiebra:

"Confirmado el temor de los inversionistas, Enron Corp. presentó 
un extenso documento de divulgación a la Comisión de Bolsa y Valores de Estados Unidos (SEC), declarando que sus estados financieros desde 1997 "no son confiables" y que tendrán que revisarse.

Entre otros problemas, Enron reconoció que exageró sus ganancias netas por un total de US\$. 586 millones, o un 20\%. Durante mucho tiempo, los estados financieros de Enron han sido criticados por considerarse indescifrables. Pero ahora resulta que simplemente estaban mal".

Asimismo, entre otras cosas importantes, dice lo siguiente:

"Según los principios de contabilidad aceptados (GAAP) el pago que recibe una empresa cuando emite acciones sólo cuenta como capital accionario si está en efectivo. Como resultado, los balances financieros auditados de Enron en 2000 exageraron los activos de pagarés por cobrar de la compañía y el patrimonio de los accionistas en US\$ 172 millones. $Y$ sus balances sin auditar del año 2001, en US\$828 millones. Los US\$1,000 millones en exceso representan un $8,5 \%$ del patrimonio de los accionistas reportados por Enron el 30 de junio.

"Es contabilidad básica no registrar capital hasta que se reciba efectivo, y un pagaré no cuenta como efectivo" dice la Sra. Lynn Turner, una ex contadora en jefe de la SEC. "La pregunta que surge es: “ ¿cómo pudieron ambos socios y el administrador de esta auditoría dejar pasar esta simple regla básica de contabilidad?".
Un vocero de Enron dijo que el error de contabilidad fue sólo eso, un "error" y que creyeron que no fue sustancial; que se hizo las correcciones con el consentimiento de los auditores, quienes además realizaron revisiones trimestrales limitadas de los estados financieros sin auditar y revisaron las entradas que resultaron en exageraciones del capital accionario "hasta donde lo consideraron necesario".

El caso de Enron es complicado en el mundo de los negocios de EE. UU. Las cinco grandes firmas de contabilidad y auditoría, con sede en este país del norte, han sido golpeadas con múltiples debacles contables entre clientes importantes, afirma el Sr. Well de The Wall Street Journal.

Por otro lado, al cierre de enero de 2002 , los redactores del The Wall Street Journal, resumen el problema al decir que "las dramáticas consecuencias derivadas de la incapacidad para descifrar los números de Enron han activado las alarmas y han hecho que los focos se centren ahora sobre otros gigantes de los negocios". Las operaciones que llaman la atención son:

1. Capacidad de una empresa gigante para generar beneficios sostenidos durante dos décadas dada la naturaleza cíclica de muchos de sus negocios. Los expertos reconocen no saber cuál es el secreto del éxito y apuntan a una empresa subsidiaria como posible fuente del misterio.

2. Empresa gigante que ha mantenido alto el listón de las ganancias durante 15 años. Los expertos aseguran verse superados por la complejidad contable con cientos de subsidiarias.

3. Otra empresa gigante que ha desquiciado a más de uno al introducir en sus balances la inexplicable categoría de "otros ingresos".

4. Empresa gigante y su supuesta tendencia a utilizar subsidiarias y franquicias para impulsar los beneficios. 
La labor fiscalizadora en EE. UU, también muestra debilidades de control, cuando se lee lo expresado por los Srs. Jonathan Weil y Scot J. Paltrow, redactores del Journal, que dicen:

"Cuando Harvey Pitt se convirtió en agosto en presidente de la Comisión de Bolsa y Valores (SEC) de EE. UU., los empleados de la SEC dejaron de trabajar en un largo informe detallando que existian severas deficiencias en la forma en la que se autorregulaban las firmas de contabilidad.

Documentos adjuntos al borrador determinaron que al realizar revisiones recíprocas, las cinco grandes firmas de contabilidad repetidamente sacaron a la luz lo que el personal de la SEC calificó de grandes imperfecciones en la forma en que se llevaban a cabo las auditorías, pero a pesar de eso se otorgaron unas a otras credenciales de buena salud en los informes públicos de las citadas revisiones. $E l$ abortado informe de la SEC iba a incluir críticas detalladas de las revisiones individuales, así como propuestas para impulsar la supervisión del sector contable.

El hecho de que se abandonara el proyecto implica que la SEC puso a un lado un documento cuyas conclusiones probablemente hubieran diferido significativamente del plan para reformar la supervisión de las auditoras, destacó Pitt el 17 de enero, según una fuente familiarizada con el proyecto. La SEC no dio a conocer los documentos que arrojan luz sobre la debilidad en el proceso de revisión entre firmas del mismo sector, así como sobre el desempeño de las cinco grandes empresas del sector".

El 30 de enero de 2002, el redactor del Journal, Sr. Gregory Zuckerman escribe lo siguiente:

"Las acciones cayeron drásticamente el martes en medio de un fuerte volumen de negociación ante las crecientes inquietudes de que problemas contables similares a los que aquejan a Enron podrían afectar a más compañías, afligiendo a todo el mercado.

Con las acciones aún negociándose a precios históricamente altos, las crecientes dudas acerca de la legitimidad de los resultados de un gran número de empresas podría afectar el mercado de valores en el futuro inmediato, según algunos operadores.

Si los inversionistas se vuelven más reacios al riesgo, eso rebajaría el precio que están dispuesto a pagar por los resultados de todo tipo de empresas, inclusive si la economía se recupera este año, dicen los operadores".

Como caso especial, se cita a la empresa Sun Microsystems, que el 20 de enero de 2000 , anunció que vendería 18000 servidores a Enron y que ambas empresas esperaban un crecimiento explosivo en el negocio de la banda ancha. Las acciones de Enron se dispararon en un $26 \%$ en un día de US\$ 53,50 a US\$ 67,38.

El siguiente cuadro sintetiza esta operación: 


\section{INFORMACIÓN PRIVILEGIADA}

Antes de anunciar un contrato con Sun Microsystem, Enron hizo una cobertura que habría puesto un límite a los movimientos de su acción. Abajo, los cierres diarios de las acciones de Enron antes y después del anuncio.

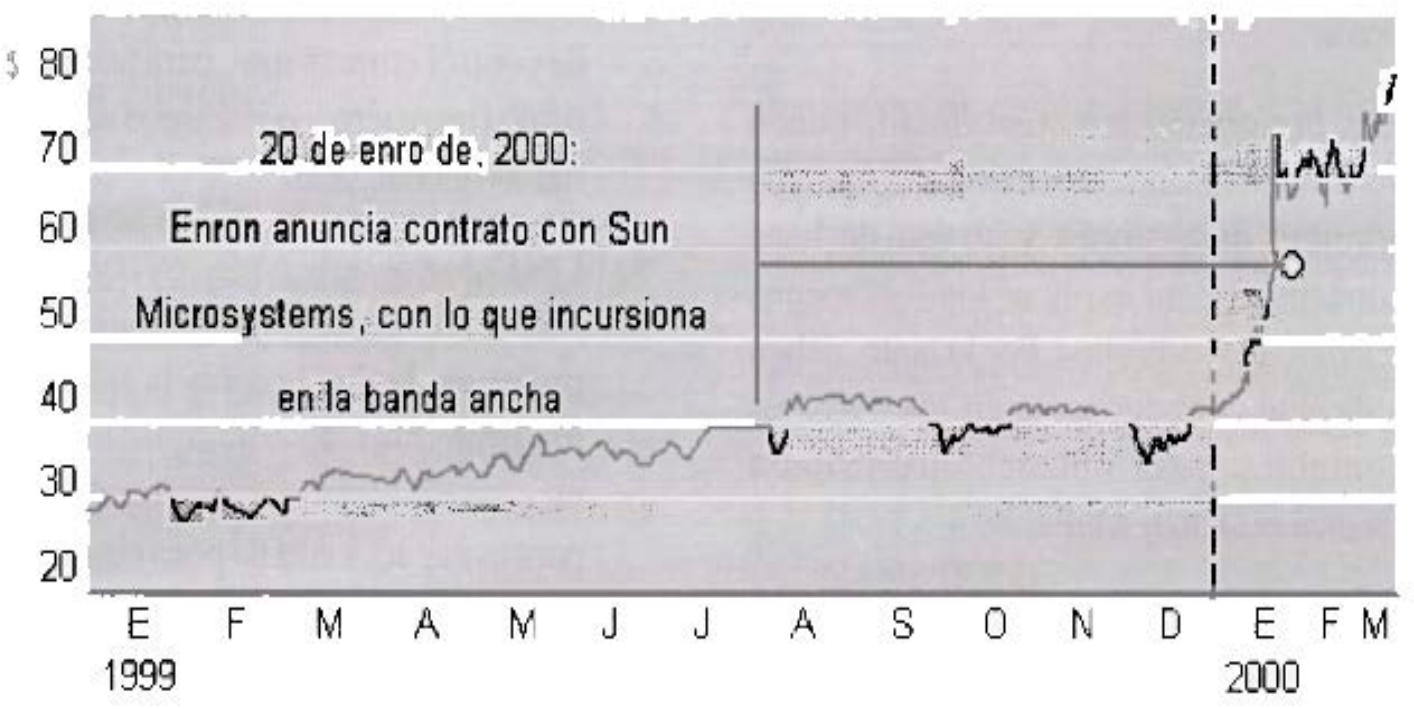

Un analista cuenta que sus colegas entusiasmados corrían por los pasillos para comunicar por teléfono sobre el acuerdo, producido en el apogeo del auge tecnológico: los contratos de acceso a la red estadounidense de fibra óptica de Enron superarían los US\$ 5000 millones en el año 2004, en comparación con los US\$160 millones del año 2000.

Por otro lado, veamos la debacle financiera de Enron, cuando el 23 de agosto de 2001, el analista Sr. Daniel Scotto de BNP Baribas de Nueva York dijo a sus clientes que "los papeles de Enron deberían ser vendidos a cualquier costo, y ahora mismo". El siguiente gráfico muestra como el valor de la acción de Enron, que en julio de 2001 llegaba a casi US $\$ 50$ por acción, en enero de 2002 baja a US $\$ 0,67$ por fracción:

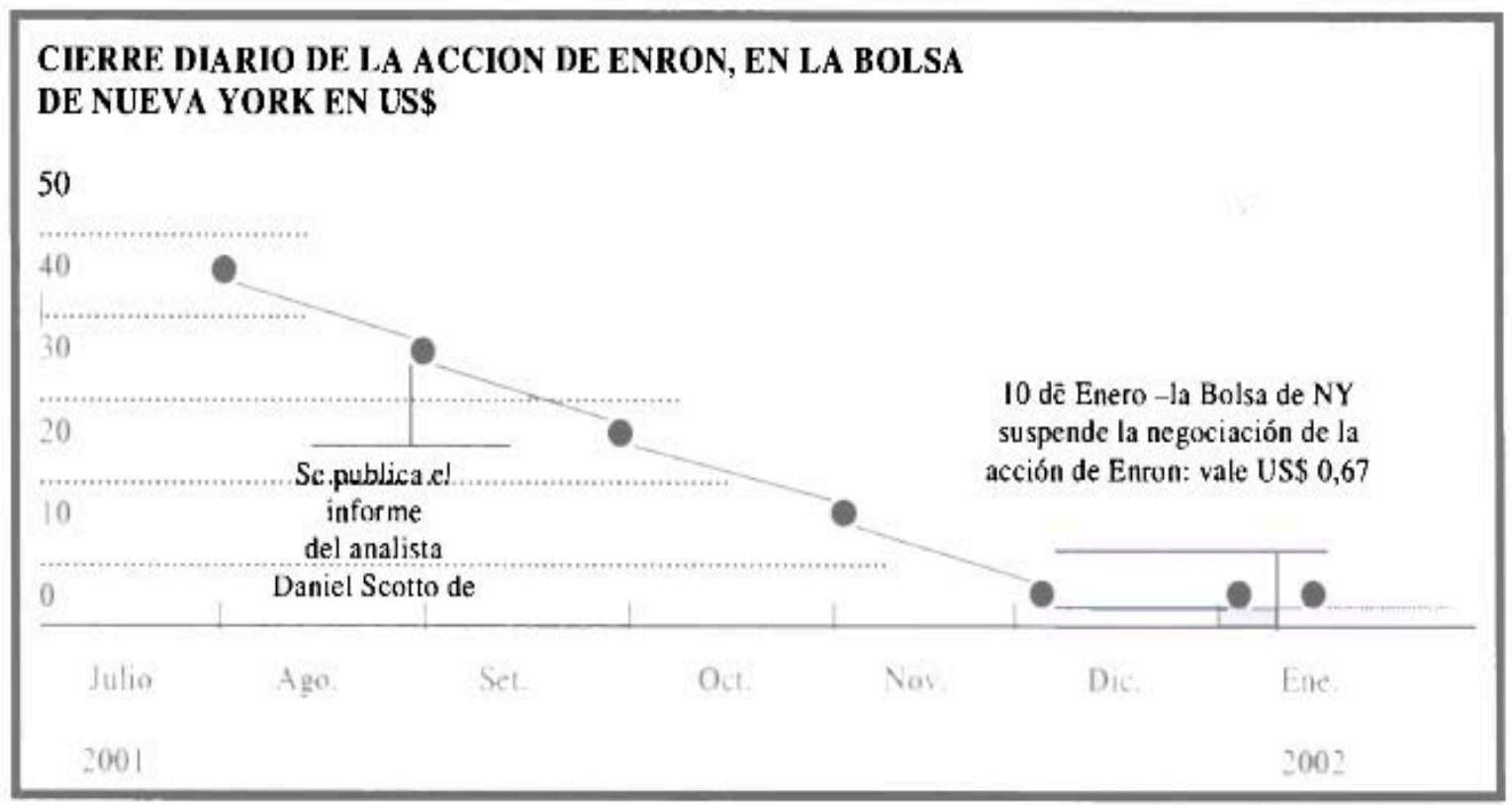


Las descripciones y comentarios dados sobre algunas operaciones contables y financieras que se han expuesto en el presente artículo, indudablemente conducen a una seria reflexión profesional, que puede resumirse en las siguientes recomendaciones finales de gran beneficio para el futuro de la profesión contable en el Perú:

1. Los principios de contabilidad, tienen verdaderos fundamentos axiomáticos que no admiten discusiones y sirven de base conceptual para explicar los fenómenos relacionados con ellos. Por lo tanto, deben aplicarse correctamente en los registros contables, para obtener información financiera veraz y confiable.

2. La auditoría financiera se planifica en base a un apropiado estudio y una evaluación del sistema de control interno existente, de manera que se pueda confiar en él para determinar la extensión y oportunidad de los procedimientos a aplicarse. Cuando el auditor emite el dictamen, debe expresar claramente el carácter de su examen, su alcance y su opinión razonable sobre toda la información contenida en los Estados Financieros. Si toma decisiones para revisar y auditar determinadas áreas financieras y de resultados, debe anotar en el mismo dictamen, las razones que lo llevaron a efectuar dichos trabajos parciales de auditoría y no simplemente describir tales áreas sólo para conocimiento de los usuarios.

3. Ante los continuos cambios operativos de una empresa, tanto el contador como el auditor deben mantener un sólido criterio profesional para ejecutar sus respectivas tareas y mantener su independencia, frente a los vaivenes económicos y financieros que realizan los ejecutivos, motivados por el deseo de alcanzar altos márgenes de utilidades de dudosa procedencia o ejecutar traslados de deudas y obligaciones por pagar, a otras empresas del mismo grupo económico, para mostrar forzados equilibrios contables.

4. Es necesario alertar a las autoridades fiscalizadoras del Perú sobre la necesidad de actualizar los procedimientos existentes de control empresarial, para adecuarlos al ritmo financiero y económico del presente mundo globalizado.

5. Los Colegios de la profesión contable en el Perú deben mantener adecuada supervisión profesional sobre la correcta aplicación de los principios de contabilidad y de los procesos de registro contable y de auditoría para evitar acciones de poca credibilidad.

6. Las facultades de contabilidad del Sistema Universitario Peruano, deben incluir en sus planes curriculares, estudios teóricos y prácticos de control financiero y económico empresarial aplicable al constante crecimiento de las operaciones financieras globalizadas.

\section{BIBLIOGRAFÍA}

Colegio de Contadores Públicos de Lima. Declaraciones sobre normas de auditoría SAS. Lima , 1998.

Colegio de Contadores Públicos de Lima. Normas Internacionales de Auditoría NIAS. Lima, 1998.

Millán Puentes, Regulo. La contabilidad como ciencia. Colombia, Edit. Kimpres, 1999.

Sinesterre V. Gonzalo y Polanco Luis E. Contabilidad gerencial. Información para la toma de decisiones. Colombia, ELDE Edit. 1994. 